\title{
Interactions of SARS Coronavirus Nucleocapsid Protein with the host cell proteasome subunit p42
}

\author{
Qin Wang1', Chuan Li², Quanfu Zhang1', Tao Wang², Jiandong Li', Wuxiang Guan'1, Jianshi Yu' ${ }^{1}$ Mifang Liang*2 and \\ Dexin Li*1
}

\begin{abstract}
Background: Severe acute respiratory syndrome-associated coronavirus (SARS-CoV) spreads rapidly and has a high case-mortality rate. The nucleocapsid protein (NP) of SARS-CoV may be critical for pathogenicity. This study sought to discover the host proteins that interact with SARS-CoV NP.

Results: Using surface plasmon resonance biomolecular interaction analysis (SPR/BIA) and matrix-assisted laser desorption/ionization time of flight (MALDI-TOF) mass spectrometry, we found that only the proteasome subunit p42 from human fetal lung diploid fibroblast (2BS) cells bound to SARS-CoV NP. This interaction was confirmed by the glutathione S-transferase (GST) fusion protein pulldown technique. The co-localization signal of SARS-CoV NP and proteasome subunit p42 in 2BS cells was detected using indirect immunofluorescence and confocal microscopy. p42 is a subunit of the $26 \mathrm{~S}$ proteasome; this large, multi-protein complex is a component of the ubiquitin-proteasome pathway, which is involved in a variety of basic cellular processes and inflammatory responses.

Conclusion: To our knowledge, this is the first report that SARS-CoV NP interacts with the proteasome subunit p42 within host cells. These data enhance our understanding of the molecular mechanisms of SARS-CoV pathogenicity and the means by which SARS-CoV interacts with host cells.
\end{abstract}

\section{Background}

The outbreak of severe acute respiratory syndrome (SARS), which began in the Guangdong Province of China, spread rapidly to more than 30 countries during 2003. SARS has an acute onset, is highly transmissible and has a high case-mortality rate (approximately 10\%) $[1,2]$. During SARS infection, three phases of viral replication result in respiratory tract pathological changes and an over-exuberant host immune response. This mediates immunopathological damage of the lungs and other organs, and pulmonary fibrosis. SARS mortality is caused primarily by extensive lung damage and severe lymphopenia [3]. Approximately $10 \%$ of individuals $(6.8 \%$ of patients younger and $55 \%$ of patients older than 60 years of age) with clinical symptoms died as a consequence of

\footnotetext{
* Correspondence: mifangl@sina.com, lidx@chinacdc.cn

2 State Key Laboratory for Infectious Disease Control and Prevention, National Institute for Viral Disease Control and Prevention, China CDC 100 Ying Xin Jie, Xuan Wu Qu, Beijing 100052, China

1 State Key Laboratory for Molecular Virology and Genetic Engineering, National Institute for Viral Disease Control and Prevention, China CDC 100 Ying Xin Jie, Xuan Wu Qu, Beijing 100052, China

Full list of author information is available at the end of the article
}

immunopathological lung damage, caused by a hyperactive antiviral immune response [4].

The mechanism of the serious damage to the respiratory system caused by SARS-CoV remains unclear. At least two possibilities exist: (i) direct damage to cells and tissues by the SARS-CoV and (ii) indirect damage, mediated primarily by the cellular immune response and cytokines.

SARS-CoV nucleocapsid protein (SARS-CoV NP) is an extensively phosphorylated, highly basic, vital structural protein the primary function of which is to form a helical ribonucleoprotein complex with viral RNA (vRNA). This complex comprises the core structure of the SARS-CoV virion. A variety of functions have been ascribed to SARS-CoV NP, including packaging, transcription, and replication. However, these are based solely on known functions of the NP of other coronaviruses [5]. SARS$\mathrm{CoV} N \mathrm{NP}$ shows intrinsic multimerization and interacts with M protein, suggesting that NP is both critical to formation of the viral nucleocapsid core and is involved in virion assembly $[6,7]$. 
Sequence analysis indicates that the RNA-binding domain of SARS-CoV NP may be located at residues 178205 [8]. Motif scanning predicted a bipartite nuclear localization signal, located at residues 373-390, suggesting that this protein may play a role in the pathogenicity of SARS-CoV [9].

SARS-CoV NP is highly immunogenic. Antibodies against the nucleocapsid protein are longer lived and occur in greater abundance in SARS patients than antibodies against other viral components such as the spike, membrane and envelope proteins [10]. This may be due to the presence of higher levels of nucleocapsid protein, compared with other viral proteins, after SARS-CoV infection [11]. These data suggest that the SARS-CoV NP is strongly antigenic and so may play an important role in generation of the host immune response and immunopathological damage.

In this study, SPR/BIACORE, MALID-TOF MS, the GST-fusion expression pulldown technique, and cell colocalization were used to investigate the interactions of SARS-CoV NP with host cell proteins. In this way, we sought to further elucidate the molecular pathogenic mechanisms of SARS-CoV. This, in turn, will allow development of novel therapeutics effective against this debilitating infection.

\section{Materials and methods}

\section{Plasmids and bacterial strains}

Plasmid pET22b-SNP22b was constructed by cloning the SARS-CoV NP (SNP22b) gene by reverse transcriptase PCR (RT-PCR) using vRNA from SARS-CoV SCV-8 (isolated from a SARS patient in Beijing, China) with the following primers: forward: 5'-GAAGGATCCGATGT CTGATAATGGACCCCAATCAA-3', reverse: 5'-GCTG AATTCTTAATGGTGATGGTGATGGTGTGCCTGA GTTGAATCAGCAGAAGC-3'. PCR products were purified and inserted into the pET22b plasmid using BamHI/ EcoRI. The p42 gene was amplified by RT-PCR using mRNA from 2BS cells with the following primers: $\mathrm{p} 42$ forward: 5'-GATGAATTCATGGCGGACCCTAGAGATAAGG-3', reverse: 5'-GATCTCGAGTTACACAGGTTTGTAGTCCAATTTAG-3'. PCR products were purified and cloned into the pGEX-5X-1 plasmid (Pharmacia, GE) using XhoI/EcoRI, to generate pGEX-5X-1p42. The plasmid pcDNA3.0-SNP22b was constructed by subcloning the SNP gene, released from pET22b-SNP22b by BamHI/EcoRI, into pcDNA3.0 (Invitrogen). All of the recombinant clones were confirmed by sequencing. Escherichia coli DH5 $\alpha$ and BL21 (DE3) were obtained from Invitrogen (USA).

\section{Cell culture, transfection, and reagents}

Human fetal lung diploid fibroblast (2BS) cells (SARSCoV susceptible), were obtained from ATCC (USA) and maintained in DMEM (Invitrogen), containing 10\% fetal bovine serum (FBS) and gentamicin $(5 \mu \mathrm{g} / \mathrm{mL})$. Transfection of 2BS cells was carried out using Lipofectamine 2000 according to the manufacturer's protocol. All restriction endonucleases were purchased from New England Biolabs (UK). Horse anti-SARS-CoV NP polyclonal antibody was a gift from the Academy of Military Medical Sciences. The anti-SARS-CoV NP mAb was prepared in our laboratory, while goat anti-mouse HRP-IgG and goat anti-rabbit IgG-FITC conjugates were purchased from Sigma (USA).

\section{ELISA assay}

Microtiter plates were coated with anti-SARS-CoV NP $\mathrm{mAb}(5 \mu \mathrm{g} / \mathrm{mL})$ in bicarbonate buffer $\left(15 \mathrm{mM} \mathrm{Na}_{2} \mathrm{CO}_{3}\right.$, $35 \mathrm{mM} \mathrm{NaHCO} 3, \mathrm{pH} 9.6)$ overnight at $4^{\circ} \mathrm{C}$. Plates were washed with PBST $\left(100 \mathrm{mM} \mathrm{NaCl}, 10 \mathrm{mM} \mathrm{Na} \mathrm{HPO}_{4}, 3\right.$ $\mathrm{mM} \mathrm{KH} \mathrm{PO}_{4}, 0.05 \%$ (v/v) Tween 20, pH 7.2) and blocked using $5 \%(\mathrm{w} / \mathrm{v})$ fat-free milk in PBST for $1 \mathrm{~h}$ at $37^{\circ} \mathrm{C}$. Plates were then washed with PBST and increasing concentrations of SARS-CoV NP added. SARS-CoV NP, bovine serum albumin (BSA), and PBS were the positive, negative, and blank controls, respectively. All plates were then incubated at $37^{\circ} \mathrm{C}$ for $1 \mathrm{~h}$, followed by washing six times with PBST. All wells were incubated with antiSARS-CoV NP horse polyclonal antibody-HRP conjugate for $1 \mathrm{~h}$ at $37^{\circ} \mathrm{C}$. Plates were subsequently washed six times with PBST; TMB chromogenic substrate solution and stop solution were then added and the $\mathrm{A}_{450}$ was determined.

\section{Immunoblot analysis}

Samples were lysed in $1 \times$ loading buffer $(0.08 \mathrm{M}$ Tris, $2.0 \%(\mathrm{w} / \mathrm{v}) \mathrm{SDS}, 10 \%(\mathrm{v} / \mathrm{v})$ glycerol, $0.1 \mathrm{M}$ dithiothreitol, $0.2 \%(\mathrm{w} / \mathrm{v})$ bromophenol blue, $\mathrm{pH}$ 6.8). Samples were boiled for $10 \mathrm{~min}$ and resolved by one-dimensional SDSPAGE. Proteins were transferred onto nitrocellulose membranes and the membranes were probed with the appropriate primary antibody. Secondary antibodies were alkaline phosphatase-conjugated anti-human, anti-rabbit, anti-mouse, or anti-goat IgG (Jackson Immunoresearch, Inc.). Gels were stained using 5-bromo-4-chloro-3-indolyl phosphate (BCIP) and nitro blue tetrazolium (NBT) solutions (Sigma).

\section{Expression, identification, and purification of recombinant SARS-CoV NP}

Plasmid pET22b-SNP22b was transformed into $E$. coli BL21. The fusion protein SNP-His was expressed under 1 $\mathrm{mM}$ IPTG at $22^{\circ} \mathrm{C}$ for $12 \mathrm{~h}$. Bacteria were harvested and lyzed in lysis buffer ( $1 \mathrm{mg} / \mathrm{mL}$ lysozyme (Sigma), $1 \%$ (v/v) Triton X-100, $5 \mu \mathrm{g} / \mathrm{mL}$ DNAse, $5 \mu \mathrm{g} / \mathrm{mL}$ RNAse) at $4^{\circ} \mathrm{C}$ for $30 \mathrm{~min}$. Lysates were harvested by centrifugation $\left(3,000 \times g, 30 \mathrm{~min}, 4^{\circ} \mathrm{C}\right)$. SARS-CoV NP levels in superna- 
tants were determined by Western blotting using antiSARS-CoV NP horse polyclonal IgG as the primary antibody.

SARS-CoV NP was purified by affinity chromatography using His. Bind ${ }^{\circ}$ Resin (Novagen) and ion exchange chromatography, using the Econo pac High CM cartridge (Bio-Rad). Purified NP was desalted using a PD-10 desalting column (Amersham) and concentrated by ultrafiltration using Centricon ${ }^{\mathrm{TM}}$ centrifugal filters $(10 \mathrm{kDa}$ MWCO, Millipore). Purified NP was suspended in HBS-EP buffer ( $\mathrm{pH} 7.4$, appropriate for BIAcore). SARS-CoV NP concentration was determined using a BCA protein assay reagent kit (Pierce). SARS-CoV NP activity was detected by indirect ELISA with anti-SARS-CoV NP horse polyclonal antibody.

\section{Identification of SARS-CoV NP-binding host cellular proteins}

2BS cells were washed twice in cold $1 \times$ PBS and harvested. Pellets were lysed in $700 \mu \mathrm{L}$ lysis buffer ( $1 \%$ Nonidet $\mathrm{P} 40$ and $20 \mu \mathrm{L}$ protease inhibitor cocktail set III (Calbiochem) in $1 \mathrm{~mL}$ HBS-EP Buffer (pH 7.4, BIAcore), followed by freezing at $-70^{\circ} \mathrm{C}$ and thawing at room temperature three times. Cells were harvested by centrifugation $\left(12,000 \times g, 20 \mathrm{~min}, 4^{\circ} \mathrm{C}\right)$. Supernatant was collected, aliquoted, and stored at $-70^{\circ} \mathrm{C}$.

Host cell protein capturing was performed on a Sensor Chip CM5 (Amersham Bioscience) using BIAcore3000 and the amine coupling direct capture method, as described by the manufacturer. Briefly, SARS-CoV NP was diluted in $10 \mathrm{mM} \mathrm{NaAc}(\mathrm{pH}$ 5.5). A Sensor Chip CM5 flow cell was activated with $70 \mu \mathrm{L}$ of a mixture of EDC/NHS (Amine Coupling Kit, Amersham Bioscience), SARS-CoV NP $(70 \mu \mathrm{L}, 80 \mu \mathrm{g} / \mathrm{mL})$ injected, and the flow cell was blocked using ethanolamine $(70 \mu \mathrm{L}, 1 \mathrm{M})$. Host cell lysate was then injected and allowed to flow through the cell containing immobilized SARS-CoV NP. A flow cell immobilized with HBS-EP buffer through which an identical volume of host cell lysate flowed represented the negative control. Lysis buffer, injected into a flow cell immobilized with SARS-CoV NP, functioned as the blank control. The reaction unit (RU) of SARS-CoV NP is obtained thus: $R U_{\text {reaction }}-R U_{\text {blank control }}-R U_{\text {negative control }}=$ RU SARS-CoV NP

Captured proteins were precipitated by addition of a three-fold volume of cold acetone at $-20^{\circ} \mathrm{C}$ overnight. Pellets were dissolved in HBS-EP buffer $(10 \mu \mathrm{L})$ and $2 \times$ loading buffer $(10 \mu \mathrm{L})$ and then resolved by $1-\mathrm{D}$ SDS-PAGE on a $12 \%$ gel. The gel was stained using modified Neuhoff's colloidal Coomassie blue G-250 stain solution (0.12\% (w/v) Coomassie Blue G-250 dye, 10\% (w/v) ammonium sulfate, $10 \%(\mathrm{v} / \mathrm{v})$ phosphoric acid, $20 \%(\mathrm{v} / \mathrm{v})$ methanol) [12].
Protein bands of interest were cut out of the gel and rinsed twice in 50\% (v/v) methanol (HPLC grade). In-gel digestion was performed using sequencing-grade modified trypsin (Promega). Extracted peptides were analyzed by matrix-assisted laser desorption ionization time-offlight (MALDI-TOF) mass spectrometry by the Life Science Academy of Beijing University, China using an Ultraflex $^{\text {TM }}$ MALDI-TOF/TOF (Bruker) and Data Explorer (v. 4.0). Proteins were identified by comparison of their monoisotopic masses with those in the NCBI nonredundant or SwissProt databases using the MS-Fit search engine of ProteinProspector.

\section{Pulldown assay}

E. coli BL21 were transformed with the pGEX-5X-1-p42 plasmid. The fusion protein p42-GST was expressed by addition of IPTG $(1 \mathrm{mM})$ at $22^{\circ} \mathrm{C}$ for $12 \mathrm{~h}$. E. coli were lysed in lysis buffer (20 mM Tris- $\mathrm{HCl}$ (pH 8.0), $200 \mathrm{mM}$ $\mathrm{NaCl}, 1$ mM EDTA (pH 8.0), 0.5\% NP40). SDS-PAGE and immunoblotting (anti-GST mAb, Pharmacia) were used to identify soluble expression of the p42-GST fusion protein.

Glutathione Sepharose 4B beads (Pharmacia, GE) were suspended in lysis buffer to a concentration of $50 \%(\mathrm{w} / \mathrm{v})$. Lysates of E. coli expressing the p42-GST fusion protein $(1 \mathrm{~mL})$, lysates of $E$. coli expressing GST alone, and lysis buffer represented the test sample, negative control, and blank control, respectively. Glutathione Sepharose 4B beads and bacterial lysates were added into three tubes, mixed for $60 \mathrm{~min}$ at $4^{\circ} \mathrm{C}$, and $40 \mu \mathrm{L}$ of this mixture was saved for SDS-PAGE analysis. The remaining mixture was washed with lysis buffer three times. Pellets were suspended in lysis buffer $(200 \mu \mathrm{L})$, to which was added purified SARS-CoV NP $(100 \mu \mathrm{L})$ and the mixture was further incubated at $4^{\circ} \mathrm{C}$. After $3 \mathrm{~h}$, the reaction mixture was washed three times in cold lysis buffer and eluted by boiling in $2 \times$ loading buffer. Eluted materials were subsequently analyzed by immunoblotting.

\section{Immunofluorescent (IF) assay}

2BS cells were cultured on coverslips in 6-well plates to $70-80 \%$ confluence and transfected with plasmid pcDNA3.0-SNP22b using the lipofectAMINE ${ }^{\mathrm{rm}} 2000$ transfection kit (Invitrogen). At $48 \mathrm{~h}$ after transfection, coverslips were washed in $1 \times$ PBS and fixed in $1 \%$ paraformaldehyde. Coverslips were then blocked with $5 \%(\mathrm{w} /$ v) skimmed milk at $37^{\circ} \mathrm{C}$ for $60 \mathrm{~min}$ and washed six times in 1× PBS. Following incubation with a 1:100 dilution of mouse anti-SARS-CoV NP $\mathrm{mAb}$ and a 1:100 dilution of anti-p42 polyclonal antibody (Biomol, USA) at $37^{\circ} \mathrm{C}$ for $60 \mathrm{~min}$, coverslips were washed six times with $1 \times$ PBS. After incubation with a 1:80 dilution of goat anti-rabbit IgG-FITC (Sigma) and a 1:200 dilution of goat antimouse IgG-TRITC (Sigma) conjugates at $37^{\circ} \mathrm{C}$ for $45 \mathrm{~min}$, 
coverslips were again washed six times in distilled water and air-dried before being mounted on a slide with interspaces containing $50 \%(\mathrm{v} / \mathrm{v})$ glycerol. Photomicrographs were taken using a confocal microscope (Confocal Microscope FluoView ${ }^{\text {TI }}$ FV1000).

\section{Results}

Expression, identification and purification of SARS-CoV NP

A plasmid expression vector, pET22b-SNP22b, was constructed to express SARS-CoV NP in E. coli BL21. Expression of SARS-CoV NP was confirmed by SDSPAGE (Fig. 1A) and Western blotting using a horse polyclonal antibody against SARS-CoV NP (Fig. 1B). When expression was induced using isopropyl $\beta$-D-thiogalactopyranoside (IPTG), cells transfected with pET22bSNP22b produced large amounts of SARS NP, amounting to up to $2 \%$ of total soluble protein (Fig. 1A; lanes 4 and 8).

Purification of SARS-CoV NP was achieved first by $\mathrm{Ni}^{2+}$ chelate affinity chromatography, where SARS-CoV NP was eluted using wash buffer containing imidazole $(250 \mathrm{mM})$, and then further purified by cation exchange chromatography. The purity of SARS-CoV NP achieved by means of this procedure was greater than $90 \%$. SARSCoV NP was desalted, dissolved in HBS-EP buffer, concentrated, and quantified. Indirect ELISA data suggested that purified SARS-CoV NP had a specific antibody binding activity similar to the native form (data not shown).

\section{Capture of proteasome subunit $\mathrm{p} 42$ by SARS-CoV NP}

SARS-CoV NP was diluted to $140 \mu \mathrm{g} / \mathrm{mL}$ in $10 \mathrm{mM} \mathrm{NaAc}$ (pH 5.5) for immobilization. Regeneration was achieved
A

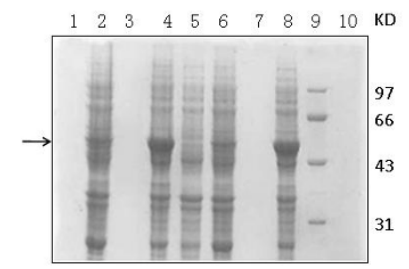

B

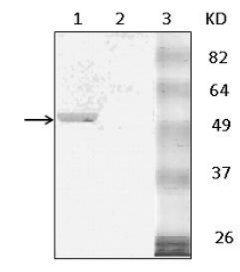

Figure 1 Expression and Identification of SNP22b (SARS-CoV NP). (A) Supernatants (lanes 1 and 10) and pellets (lanes 2 and 6) of E. coli BL21 containing the pET22b-SNP22b vector expressing SARS-CoV NP, without IPTG induction. Supernatants (lanes 3 and 7) and pellets (lanes 4 and 8) of E. coli BL21 containing the pET22b-SNP22b vector and expressing SARS-CoV NP, induced with IPTG. Pellets of E. coli BL21 containing pET22b induced with IPTG (lane 5). Molecular weight markers (lane 9). The position of SARS-CoV NP ( 47 kDa) is indicated by an arrow. (B) Western blot analysis of SARS-CoV NP using an anti-SARS-CoV NP horse polyclonal antibody. Lysate of E. coli BL21 expressing SARSCoV NP, induced by IPTG (lane 1). Lysate of E. coli BL21 containing pET22b induced by IPTG (lane 2). Molecular weight markers (lane 3). The position of SARS-CoV NP ( 47 kDa) is indicated by an arrow. using $\mathrm{NaOH}(50 \mathrm{mM})$. Immobilization of SARS-CoV NP in a sensor chip CM5 flow cell resulted in an RU value of 12355.1. This increased to 31 after HBS-EP buffer was immobilized in an adjacent flow cell of the same chip and increased further upon addition of 2BS cell lysates to the flow cell containing SARS-CoV NP. A stable level (1120 RU) was achieved after a total of $70 \mu \mathrm{L} 2 \mathrm{BS}$ cell lysate was injected. The flow cell was then washed six times and $\mathrm{NaOH}(5 \mu \mathrm{L}, 50 \mathrm{mM})$ was injected to elute proteins bound to SARS-CoV NP. The RU values of the blank and negative controls were $23 \mathrm{RU}$ and $41 \mathrm{RU}$, respectively. Thus, the specific reaction of SARS-CoV NP and 2BS cell lysate was quantified as $1056 \mathrm{RU}$ (calculated by 1120RU23RU-41RU), suggesting that SARS-CoV NP had bound to at least one protein present in 2BS cell lysate (Fig. 2A). Captured proteins were recovered and collected by repeating the direct capture and blank control procedures.

The protein(s) captured by SARS-CoV NP were precipitated, resolved by 1D SDS-PAGE and visualized using modified Neuhoff's colloidal Coomassie blue G-250 staining. SARS-CoV NP was found to have bound three proteins from $2 \mathrm{BS}$ cell lysate, the molecular weights of which ranged from 43 to $66 \mathrm{kDa}$ (Fig. 2B, lane 3). No protein was captured from the blank or negative controls (Fig. 2B, lanes 1,2). Analysis by MALID-TOF mass spectrometry identified the proteins as: $26 \mathrm{~S}$ proteasome regulatory subunit $\mathrm{S} 10 \mathrm{~B}$ (proteasome subunit $\mathrm{p} 42$ or proteasome 26S subunit ATPase 6, P62333; Fig. 2B), cytokeratin 1 (CK1, P04264), and cytoskeletal protein 10 (CK10, P13645). Cytokeratins are a subfamily of intermediate filament proteins. Cytokertin 1 (CK1) has the highest molecular weight and the highest isoelectric point of the family, while cytokeratin 10 has the lowest molecular weight and a low isoelectric point. These proteins are expressed in combinations that vary according to the type of epithelium within which they are found. Proteasome subunit p42 was selected for further assessment; the roles of CK1 and CK10 will be considered in a subsequent study.

\section{Interaction of proteasome subunit p42 with SARS-CoV NP in vitro}

To examine further the interaction between SARS-CoV NP and proteasome subunit p42 in vitro, GST and the p42-GST fusion protein were produced, purified, and identified by 1D SDS-PAGE (Fig. 3A) and Western blotting, using an anti-GST mAb (Fig. 3B). Interaction of SARS-CoV NP with the proteasome subunit $\mathrm{p} 42$ in vitro was identified using the p42-GST fusion protein pulldown technique. Data suggested that the SARS-CoV NP was pulled down by p42-GST fusion protein (Fig. 4, lanes 6,8 ), but not by either of the negative controls: GST alone (Fig. 4, lanes 1, 3, 5, 7) or glutathione Sepharose 4B beads 
A

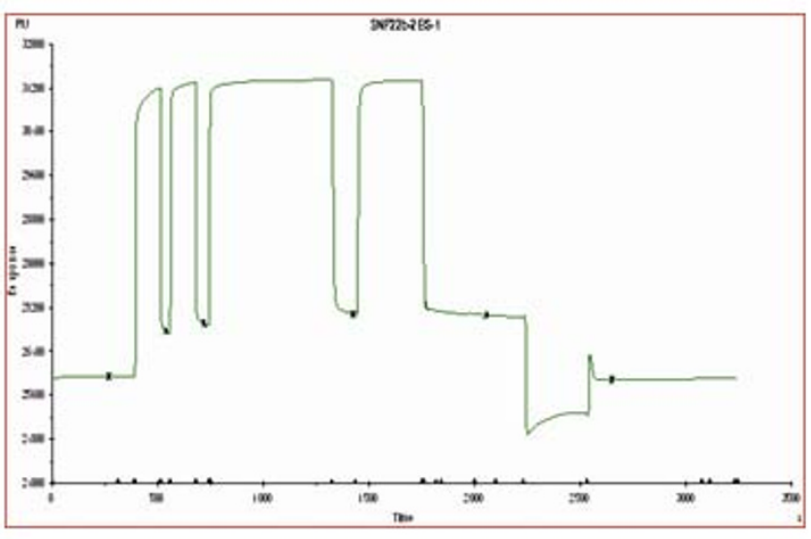

a

b

c d e
B

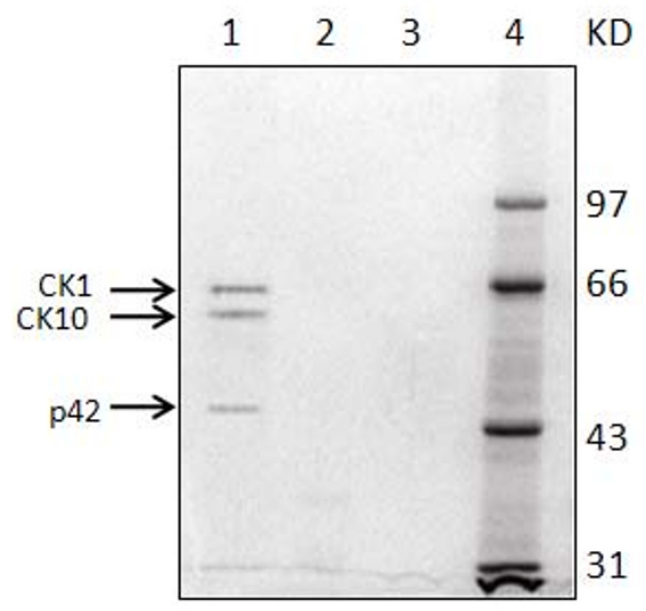

Figure 2 Identification of SARS-CoV NP-associated cellular protein(s). (A) Interaction of SARS-CoV NP with 2BS cell lysate proteins. The maximum reaction intensity was $1120 \mathrm{RU}$ (manual injection). Baseline (a), injection of host cell lysate (b), RU value of flow cell after injection of host cell lysate (reactive amount $=R U_{c}-R U_{a}$ ) (c), eluted and recovered captured proteins (d), regeneration of flow cell (e). (B) Proteins captured from 2BS cell lysate (lane 1), blank controls (lane 2), and negative controls (lane 3). Molecular weight markers (lane 4). Arrows indicate the position of captured proteins.

(Fig. 4, lanes 2, 9). Thus, these data suggest that SARS$\mathrm{CoV}$ NP exhibits a specific interaction with the proteasome subunit $\mathrm{p} 42$ in vitro.

\section{Co-localization of SARS-CoV NP and proteasome subunit p42 in 2BS cells}

To analyze the interaction of SARS-CoV NP and proteasome subunit $\mathrm{p} 42$ within host cells, SARS-CoV NP was expressed in 2BS cells and identified by indirect immunofluorescence using an anti-SARS-CoV NP mAb (Fig. 5A).

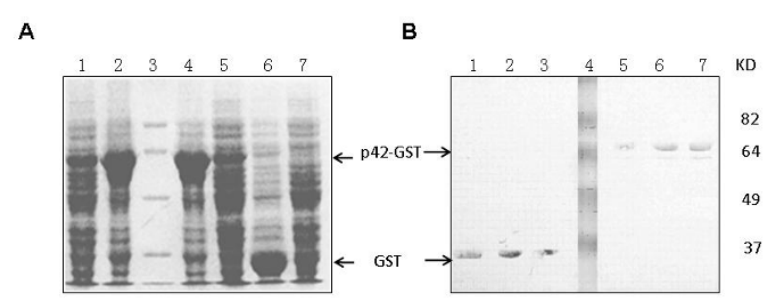

Figure 3 Expression and identification of GST and the p42-GST fusion protein. (A) Lysate of E. coli BL21 containing the pGEX-5X-1p42 vector, expressing p42-GST fusion protein without IPTG induction (lanes 1, 5) or induced by IPTG (lanes 2, 4). Lysate of E. coli BL21 containing the PGEX-5X-1 vector expressing GST with IPTG induction (lane 6) or without IPTG (lane 7). Molecular weight markers (lane 3). (B) Western blot analysis of p42-GST fusion protein and GST expression using an anti-GST mAb. Lysates of GST-expressing E. coli BL21 with IPTG induction (lanes 1, 2). Lysates of p42-GST fusion protein-expressing E. coli BL21 with IPTG induction (lanes 6, 7). Supernatants of E. coli BL21 expressing GST lysed using lysozyme (lane 3). Supernatants of E. coli BL21 expressing p42-GST fusion protein lysed by lysozyme (lane 5). Molecular weight markers (lane 4).
After transfection of 2BS cells with SNP22b-pcDNA3.0, the proteasome subunit $\mathrm{p} 42$ was detected by means of an anti-p42 antibody and anti-rabbit IgG-FITC conjugate (Fig. 5B, lane 1; excitation wavelength $488 \mathrm{~nm}$ ). Expression of SARS-CoV NP in 2BS cells was confirmed using an anti-SARS-CoV NP mAb and anti-mouse IgG-TRITC conjugate (Fig. 5, lane 2; excitation wavelength $568 \mathrm{~nm}$ ). Thus, the co-localization signals (Fig. 5, lane 3; excitation

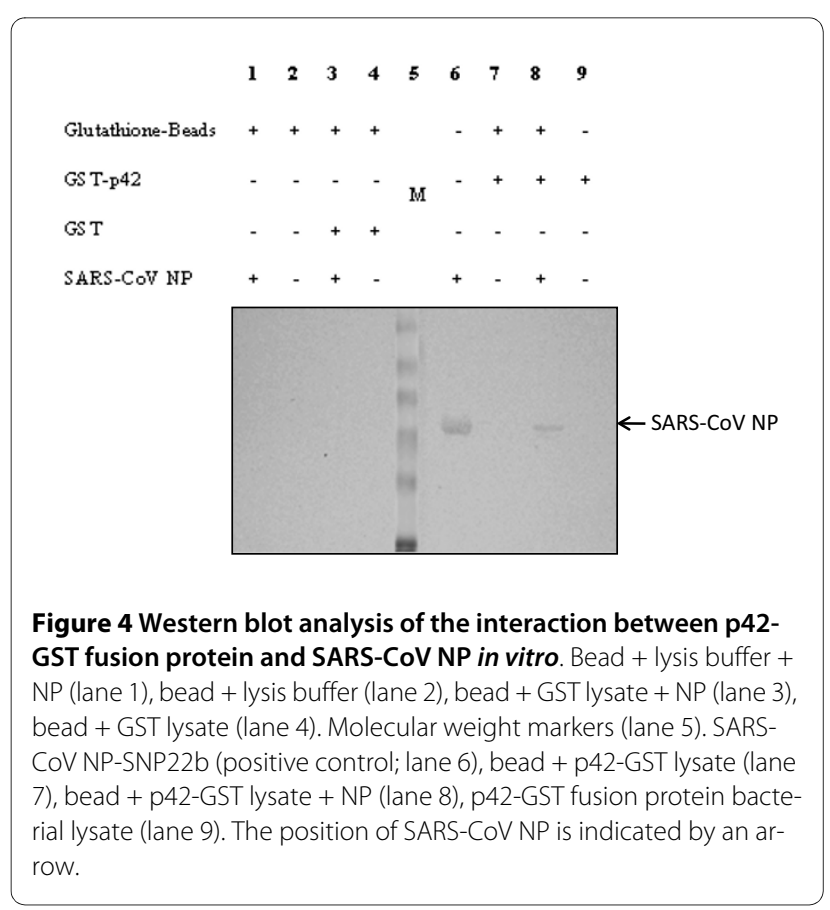


A

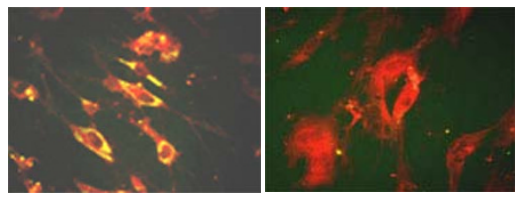

B

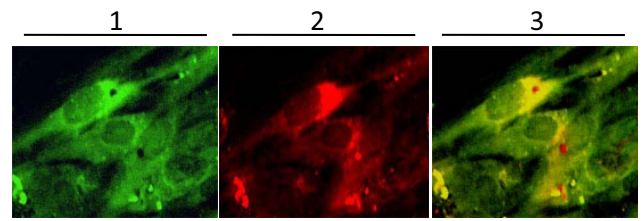

Figure 5 Co-localization of SARS-CoV NP and p42 in 2BS cells. (A) SARS-CoV NP was expressed in 2BS cells transfected with recombinant -pcDNA3.0+SNP22b (left panel), 2BS cells transfected with pcDNA3.0 (right panel; negative control). (B) Proteasome subunit p42 in 2BS cells localized with anti-p42 antibody and anti-rabbit lgG-FITC conjugate, excitation at $488 \mathrm{~nm}$ (lane 1). SARS-CoV NP expressed in 2BS cells, localized using an anti-SARS-CoV NP mAb and anti-mouse IgG-TRITC conjugate, excitation at $568 \mathrm{~nm}$ (lane 2). Co-localization was detected by merging lanes 1 and 2 (lane 3).

by both $488 \mathrm{~nm}$ and $568 \mathrm{~nm}$ ) of p 42 and SARS-CoV NP in 2BS cells were elucidated by merging lane 1 and lane 2 of Fig 4 . This usually occurs when fluorescently labeled molecules bind to targets in close proximity.

\section{Discussion}

SARS is an emerging infectious disease that has become a global public health concern in the $21^{\text {st }}$ century. However, the pathogenesis of SARS remains unclear. It has been suggested that the cytokine storm observed during the early stages of SARS in most patients contributes to the progression of systemic inflammatory response syndrome [13]. The SARS-CoV NP has been shown to be highly immunogenic and the predominant target for the humoral immune response during infection with SARS$\mathrm{CoV}$ [14]. This process may trigger cytokine production and so induce apoptosis in host cells [13].

Law suggested that SARS-CoV, during infection of dendritic cells, evades the immune response by down-regulating expression of the anti-viral chemokines IFN- $\alpha, \beta$ and $\gamma$ and IL-12p40, while simultaneously up-regulating that of others: for example, TNF- $\alpha$, IL- 6 , MIP- $1 \alpha$, and IP10 [15]. Additionally, it seems likely that proinflammatory cytokines released by macrophages in pulmonary alveoli play an important role in the pathogenesis of SARS.

SARS-CoV is capable of inducing apoptosis of Vero E6 cells in vitro [16]. Apoptosis of T- and B-lymphocytes in the immune organs and pulmonary alveoli and mononuclear inflammatory infiltration in the lungs, lymph nodes, and spleens of SARS-CoV infected individuals has been observed. Some SARS-CoV proteins, for example, E protein, NP, ORF7a, ORF3a, and ORF3b, have been shown to induce apoptosis in vitro [13,17-19]. Thus, the rapid apoptosis induced by SARS-CoV may be one of the mechanisms responsible for the damage to the lungs and immune organs observed in SARS patients.

Interaction of viral and host proteins may contribute to the processes involved in viral infection, replication, and assembly and so increasing our knowledge of these interactions may lead to increased insight into the pathology, clinical manifestations, and pathogenesis of SARS. Li et al. reported in 2003 that angiotensin-converting enzyme 2 acted as a functional receptor for the SARS-CoV by binding to SARS-CoV S protein [20]. To further examine the role of such interactions in the pathogenesis of SARS$\mathrm{CoV}$ infection, we investigated the ability of SARS-CoV nucleocapsid protein to bind to host cell proteins. The prokaryotic expression vector $\mathrm{pET} 22 \mathrm{~b}$ was used for soluble expression of SARS-CoV NP. This vector contains the PeIB signal peptide to assure correct conformation of NP in E. coli. Because the SARS-CoV NP, unlike other SARS$\mathrm{CoV}$ proteins, contains no glycosylation site, the recombinant form shows identical immune reactivity to that of the native protein [21].

Data suggested that the proteasome subunit $\mathrm{p} 42$ of 2BS cells interacted with SARS-CoV NP. To our knowledge, this is the first report of such an interaction. Proteasome subunit $\mathrm{p} 42$ (also called the $26 \mathrm{~S}$ protease regulatory subunit S10B) is a subunit of PA700 in the ubiquitin-proteasome pathway (UPP). This pathway is one of a number of intracellular proteolytic systems in eukaryotes and mediates ATP-dependent degradation of ubiquitinated proteins. The 26S ATP-dependent proteasome, formed from the $20 \mathrm{~S}$ proteasome and $19 \mathrm{~S}$ regulatory particle (PA700), is a multi-protein complex. The $20 \mathrm{~S}$ component has proteolytic activity, while the PA700 component binds ubiquitinated proteins and promotes their degradation by the $20 S$ component. Consistent with its ATPase activity, the proteasome subunit $\mathrm{p} 42$ contains an ATP binding region in a conserved 200 aa domain. The proteasome subunit $\mathrm{p} 42$, together with the five other subunits, TBP1, MSS1, S4, p45, and TBP7, assemble to form the PA700 component. 26S proteasomes are distributed in the cytoplasm and nucleolus $[22,23]$. The ubiquitin-proteasome pathway mediates turnover of intracellular proteins. It plays a central role in the degradation of short-lived and regulatory proteins that are themselves vital for correct functioning of a variety of basic cellular processes including regulation of the cell cycle, modulation of cell surface receptor and ion channel expression, and antigen processing and presentation [24].

While proteasomes do hydrolyze endogenous proteins, they are also capable of degrading exogenous proteins: for 
example, viral peptides. In this way, these complexes are involved in defenses against viral infection. Interactions between viruses and UPP have recently been reported. Hepatitis B virus X protein (HBX) has been demonstrated to target the proteasome complex after viral entry into the cell [25]. Hu revealed that HBX is both a substrate and a potential inhibitor of the proteasome complex. The authors suggested that HBX may inhibit proteasomemediated proteolysis by binding two subunits (Sub4, Sub7) of the $26 \mathrm{~S}$ proteasome [26]. HBX expression inhibited turnover of c-Jun and ubiquitin- arginine- $\beta$-galactosidase, both known substrates of UPP [27]. HIV1 Tat protein was shown to inhibit the degradative activity of $20 \mathrm{~S}$ proteasomes, by interacting with the S6a subunit of the 26S component [28]. Adenovirus E1A protein enhanced degradation of topoisomerase II alpha protein, via interaction with the S8 subunit of the $26 \mathrm{~S}$ component [29].

Evidence to date suggests that viruses employ two strategies for proteasome inhibition; first, interference with the antigen presentation activity of the proteasome, thus promoting immune evasion. Second, stimulation of the degradative activity of the $26 \mathrm{~S}$ proteasome causes an acceleration of G1/S turnover, thus promoting viral replication by interference with the cell cycle [30]. During viral infection, UPP hydrolyzes viral proteins into short peptides, which are then presented to CTL via MHC-1. Activated CTL then attack virally infected cells. The transcription factor nuclear factor- $\mathrm{KB}(\mathrm{NF}-\mathrm{\kappa B})$ is involved in regulation of immunity and inflammation; the UPP plays a central role in the regulation of NF- $\mathrm{kB}$ activation. When a cell is infected by a virus, $I_{\kappa} B$ is phosphorylated and hydrolyzed by UPP, thus releasing NF- $\mathrm{B}$, which enters the nucleus and activates transcription of genes encoding inflammatory responses [31]. Thus, the UPP may play a vital role in infection, and the host response to infection, by a variety of viral pathogens. Development of a specific inhibitor of UPP may have potential not only as an antiviral, but also as an anti-tumor and anti-inflammatory agent. Study of the interactions of components of the UPP with viral proteins may provide useful information relating to the pathogenesis of a number of diseases [32].

Determining potential mechanisms of the interaction of SARS-CoV NP with proteasome subunit p42 was outside the scope of this study. However, such information may enhance our understanding of the activities of proteasomes in eukaryotic cells. We assumed that the interaction between SARS-CoV NP and proteasome subunit p42 inhibited the proteolytic activity of proteasomes. The actions of SARS-CoV NP and some other viral proteins may act to increase the deleterious effect of SARS-CoV infection, resulting in increased permeability, inflammatory infiltration, and mononuclear cell soakage, perhaps even accelerating pulmonary fibrosis. Moreover, this interaction may impair proteolysis of viral proteins and their presentation to CTLs and thus aid SARS-CoV evasion of immune effectors. Furthermore, such activity may affect inflammatory processes, resulting in the immunopathological damage so common in SARS. SARS-CoV NP is post-translationally modified by covalent attachment to small ubiquitin-like modifiers. Sumoylation of NP aids in promoting homo-oligomerization and assists in interference with host cell division [33].

Whether SARS-CoV NP interacts with proteasome subunit $\mathrm{p} 42$ in vivo remains unknown, and so further studies are required to fully determine the nature of this interaction and its effect in vivo during SARS-CoV infection. Furthermore, more research on the downstream effect of this interaction may lead to the development of novel antiviral agents effective against this debilitating and often fatal infection.

\section{Conclusions}

In this study, we demonstrated for the first time that SARS-CoV NP interacts with the proteasome subunit $\mathrm{p} 42$ in vitro. This finding may lead to a new direction in research focusing on the molecular mechanisms of SARS-CoV infection and the pathogenesis of SARS. Whether the interaction of SARS-CoV NP and p42 impacts presentation of viral antigens and assists in viral evasion of CTLs and/or promotes enhanced inflammatory responses resulting in immunopathological damage remain to be determined.

\section{Abbreviations}

RNA: Ribonucleic Acid; PCR: Polymerase Chain Reaction; ELISA: Enzyme-Linked Immunosorbent Assay; DNA: Deoxyribonucleic Acid; mAb: Monoclonal Antibody; HRP: Horseradish Peroxidase; TMB: Tetramethyl Benzidine; HPLC: High Performance Liquid Chromatography; EDTA: Ethylenediamine Tetraacetic Acid IFN: Interferon; IL: Interleukin; TNF: Tumor Necrosis Factor; MIP: Macrophage Inflammatory Protein; IP: Interferon-inducible Protein; ORF: Open Reading Frame; ATP: Adenosine Triphosphate; HBX: X protein of HBV; CTL: Cytotoxic TLymphocyte; MHC: Major Histocompatibility Complex.

\section{Competing interests}

The authors declare that they have no competing interests.

\section{Authors' contributions}

QW and DL participated in the design and conducted the majority of the experiments in the study and drafted the manuscript. TW and JL contributed to the interpretation of the findings and revised the manuscript. QZ and CL carried out ELISA tests. ML edited the manuscript. JY and WG performed analyses of data. All authors read and approved the final manuscript.

\section{Acknowledgements}

This work was supported by grants from National 973 Program (No. 2003CB514115) and the Sino-British co-operation project of the Beijing Municipal Science and Technology Committee - Immunopathological study of SARS (No. H030230100130).

\section{Author Details}

'State Key Laboratory for Molecular Virology and Genetic Engineering, National Institute for Viral Disease Control and Prevention, China CDC 100 Ying Xin Jie, Xuan Wu Qu, Beijing 100052, China and 2State Key Laboratory for Infectious Disease Control and Prevention, National Institute for Viral Disease Control and Prevention, China CDC 100 Ying Xin Jie, Xuan Wu Qu, Beijing 100052, China 
Received: 21 January 2010 Accepted: 17 May 2010

Published: 17 May 2010

\section{References}

1. Peiris JS, Lai ST, Poon LL, Guan Y, Yam LY, Lim W, Nicholls J, Yee WK, Yan WW: Coronavirus as a possible cause of severe acute respiratory syndrome. The Lancet 2003, 361:1319-1326.

2. Ksiazek TG, Erdman D, Goldsmith CS: A Novel Coronavirus Associated with Severe Acute Respiratory Syndrome. N Engl J Med 2003, 348:1953-1966.

3. Tsui PT, Kwok ML, YUEN H: Severe acute respiratory syndrome: clinical outcome and prognostic correlates. Emerg Infect Dis 2003, 9:1064-1069.

4. Nicholl JM, Poon LL, Lee KC: Lung pathology of fatal severe acute respiratory syndrome. Lancet 2003, 361:1773-1778.

5. Chen ZL, Pei DC, Jiang LX, Song YJ: Antigenicity analysis of different regions of the Severe Acute Respiratory Syndrome Coronavirus nucleocapsid protein. Clin Chem 2004, 50:988-995.

6. He RT, Dobie F, Ballantine M: Analysis of multimerization of the SARS conoravirus nucleocapsid protein. Biochem Biophy Res Commun 2004 316:476-483.

7. He RT, Leeson A, Ballantine M, Andonov A, Dobie F, Li Y: Characterization of protein-protein interactions between the nucleocapsid protein and membrane protein of the SARS coronavirus. Virus Res 2004 105:121-125.

8. Shi L, Zhang QP, Rui W, Lee M, Lu M: Preliminary analysis of the structure and function of putative nucleocapsid protein. CMB/ 2003 [http:// cmbi.bjmu.edu.cn/cmbidata/sars/html/41.pdfl. (accessed June 2003)]

9. Shi L, Rui W, Lee M: Nuclear targeting sequence in SARS nucleocapsid protein. CMBI 2003 [http://cmbi.bjmu.edu.cn/cmbidata/sars/html/ 10.pdf. (accessed June 2003)]

10. Chang MS, Lu YT, Ho ST: Antibody detection of SARS-CoV spike and nucleocapsid protein. Biochem Biophy Res Commun 2004, 314:931-936.

11. Rota PA, Oberste MS, Monroe SS, Nix WA, Campagnoli R, Icenogle JP: Characterization of a novel coronavirus associated with severe acute respiratory syndrome. Science 2003, 300:1394-1399.

12. Candiano $G$, Bruschi M, Musante L: Blue silver: A very sensitive colloidal Coomassie G-250 staining for proteome analysis. Electrophoresis 2004 25:1327-1333

13. Milan S, Boping L, Shahid J: The SARS coronavirus nucleocapsid protein induces actin reorganization and apoptosis in COS-1 cells in the absence of growth factors. Biochem J 2004, 383:13-18.

14. Leung DT, Tam FC, Ma CH: Antibody response of patients with severe acute respiratory syndrome targets the viral nucleocapsid. J Infec Dis 2004, 190:79-386

15. Law HK, Cheung $\mathrm{CY}, \mathrm{Ngl} \mathrm{HY}$ : Chemokine upregulation in SARS coronavirus infected human monocyte derived dendritic cells. Blood 2005, 106:2366-2374.

16. Yan H, Xiao G, Zhang J: SARS coronavirus induces apoptosis in Vero E6 cells. Med Virol 2005, 73:323-331.

17. Tan YJ, Teng E, Shen S, Tan TH, Goh PY, Fielding BC, Ooi EE, Tan HC, Lim SG, Hong W: A novel severe acute respiratory syndrome coronavirus protein, U274, is transported to the cell surface and undergoes endocytosis. J Virol 2004, 78:6723-6734.

18. Law PT, Wong CH, Au TC, Chuck CP, Kong SK, Chan PK, To KF, Lo AW, Chan $J Y$, Suen YK, Chan HY, Fung KP, Waye MM, Sung JJ, Lo YM, Tsui SK: The 3a protein of severe acute respiratory syndrome-associated coronavirus induces apoptosis in Vero E6 cells. J Gen Virol 2005, 86:1921-1930.

19. Yuan $X$, Shan $Y$, Zhao Z, Chen J, Cong Y: G0/G1 arrest and apoptosis induced by SARS-CoV 3b protein in transfected cells. Virol J 2005, 2:66.

20. Li W, Moore MJ, Vasilieva N, Sui J, Wong SK, Berne MA, Somasundaran M, Sullivan JL, Luzuriaga K, Greenough TC, Choe H, Farzan M: Angiotensinconverting enzyme 2 is a functional receptor for the SARS coronavirus. Nature 2003, 426:50-454

21. Mechin MC, Der Vartanian M, Martin C: The major subunit ClpG of Escherichia coli CS31A fibrillae as an expression vector for different combinations of two TGEV coronavirus epitopes. Gene 1996, 179:211-218

22. Brooks P, Fuertes G, Murray RZ, Bose S, Knecht E, Rechsteiner MC, Hendi KB, Tanaka K, Dyson J, Rivett J: Subcellular localization of proteasomes and their regulatory complexes in mammalian cells. Biochem J 2000 , 346:155-161.
23. Fujiwara T, Watanabe TK, Tanaka K, Slaughterc CA, DeMartinod GN: cDNA cloning of $\mathrm{p} 42$, a shared subunit of two proteasome regulatory proteins, reveals a novel member of the AAA protein family. FEBS Letters 1996, 387:184-188.

24. Tanaka K: Molecular biology of proteasomes. Mol Biol Rep 1995, 21:21-26.

25. Huang J, Kwong J, Sun EC, Liang TJ: Proteasome complex as a potentia cellular target of hepatitis B virus X protein. J Virol 1996, 70:5582-91.

26. Hu Z, Zhang Z, Doo E, Coux O, Goldberg AL, Liang TJ: Hepatitis B virus X protein is both a substrate and a potential inhibitor of the proteasome complex. J Virol 1999, 73:7231-7240.

27. Zhang Z, Torii N, Furusaka A, Malayaman N, Hu Z, Liang TJ: Structural and functional characterization of interaction between hepatitis $B$ virus $X$ protein and the proteasome complex. J Biol Chem 2000, 275:15157-15165.

28. Seeger M, Ferrell K, Frank R, Dubiel W: HIV-1 tat inhibits the $20 \mathrm{~S}$ proteasome and its $11 \mathrm{~S}$ regulator-mediated activation. J Biol Chem 1997, 272:8145-8148.

29. Nakajima T, Morita K, Ohi N: Degradation of topoisomerase lla during adenovirus E1A-induced apoptosis is mediated by the activation of the ubiquitin proteolysis system. J Biol Chem 1996, 271:24842-24849.

30. Ferrell K, Wilkinson CR, Dubiel W, Gordon C: Regulatory subunit interactions of the $26 \mathrm{~S}$ proteasome, a complex problem. Trends Biochem SciF 2000, 25:83-88.

31. Julian A: Proteasome inhibitors as therapeutic agents. Expert Opinion on Therapeutic Patents 2003, 13:45-57.

32. Nandi D, Tahiliani P, Kumar A, Chandu D: The ubiquitin-proteasome system. J Biosci 2006, 31:137-55

33. Frank QL, Han X, James P, Liu D: Sumoylation of the nucleocapsid protein of severe acute respiratory syndrome coronavirus. FEBS Letters 2005, 579:2387-2396.

doi: $10.1186 / 1743-422 X-7-99$

Cite this article as: Wang et al., Interactions of SARS Coronavirus Nucleocapsid Protein with the host cell proteasome subunit p42 Virology Journal 2010, 7:99

\section{Submit your next manuscript to BioMed Centra and take full advantage of:}

- Convenient online submission

- Thorough peer review

- No space constraints or color figure charges

- Immediate publication on acceptance

- Inclusion in PubMed, CAS, Scopus and Google Scholar

- Research which is freely available for redistribution 